\title{
NaÏve Realism ANd Illusion
}

\author{
BOYD MILLAR
}

\begin{abstract}
It is well-known that naïve realism has difficulty accommodating perceptual error. Recent discussion of the issue has focused on whether the naïve realist can accommodate hallucination by adopting disjunctivism. However, illusions are more difficult for the naïve realist to explain precisely because the disjunctivist solution is not available. I discuss what I take to be the two most plausible accounts of illusion available to the naïve realist. The first claims that illusions are cases in which you are prevented from perceiving properties you would ordinarily perceive and subsequently form a mistaken judgment about the perceived object. The second appeals to an unusual look or appearance that the perceived object instantiates. I argue that neither account is satisfactory and that, consequently, naïve realism ought to be rejected.
\end{abstract}

W

HEN you have a perceptual experience of a given object you seem to be presented with that object just as it is at that moment. One might think that naïve realism provides a particularly satisfying account of this fact. The naive realist characterizes the phenomenal character of such an experience- what it's like for you to have it-in terms of a primitive, non-representational relation of awareness or acquaintance. More specifically, naïve realism is the view that when you perceive a particular object, the phenomenology of your perceptual experience is constituted by your standing in the acquaintance relation to that object and certain of its properties. ${ }^{1}$ Consequently, the naïve realist can say that

1. The theory is sometimes also called the relational view. Similar characterizations of the theory are provided by Campbell (2002: 114-15), Smith (2002: 43-44), Martin (2004: 83), Hellie (2007: 264-65), Fish (2009: 14-15), Nudds (2009: 335), Pautz (2011: 384), Logue (2012: 222-23), and Genone (2014: 345-46). The versions of naïve realism defended by Campbell (2009), Brewer (2011: Chapter 5), and French (2014) characterize perceptual acquaintance as a three-place relation between the subject, the object and its properties, and something like viewing conditions (in the case of vision). Campbell's notion of a "standpoint" is introduced in order to account for the fact that it's possible to have phenomenally distinct experiences of a specific object or property from different vantage

Contact: Boyd Millar <millar.boyd@gmail.com> 
you seem to be presented with the object just as it is at that moment because you are presented with the object just as it is at that moment.

However, there is a cost associated with this account: naïve realism seems unable to allow for perceptual error. When you suffer an illusion the object you perceive doesn't instantiate some of the properties you perceive it as instantiatingbut you can only be perceptually acquainted with some property so long as the object you perceive actually instantiates that property. And in cases of hallucination it seems to you that you perceive an object when there is no appropriate object that you perceive-but you can only be perceptually acquainted with objects that exist. Since denying that perceptual errors occur would seem to be implausible, the apparent inability of naïve realism to allow for their occurrence has led many to reject the theory out of hand.

A number of philosophers have recently claimed that naïve realists can resolve the problem posed by perceptual error by adopting disjunctivism. ${ }^{2}$ That is, such philosophers acknowledge that the naïve realist account of perceptual phenomenology can't be extended beyond veridical perceptual experiences, but they insist that this is as it should be. Veridical and non-veridical perceptual experiences, the disjunctivist claims, are different kinds of mental states: the phenomenology of veridical perceptual experiences is constituted by acquaintance with ordinary physical objects and their properties, while the phenomenology of non-veridical perceptual experiences is not.

This disjunctivist strategy is most plausible when addressing hallucinations since such experiences don't involve perceptual contact with ordinary physical objects. As a result, the bulk of the recent literature concerning whether naïve realism can accommodate perceptual error has focused on hallucinations. ${ }^{3}$ However, the disjunctivist response is not plausible when addressing illusions precisely because such experiences involve ordinary perceptual contact with objects and at least some of their properties. Consequently, while illusions have received much less attention, they represent a greater challenge to naïve realism than do hallucinations. ${ }^{4}$

The crux of the difficulty is that, while the naïve realist has to allow that the phenomenology of an illusory experience is constituted by acquaintance with an ordinary physical object and some of its properties, it is natural to assume that the property any given illusion concerns is a property that the perceived object

points, rather than to account for illusions; consequently, I don't discuss Campbell's view in what follows. The use that Brewer makes of his third relatum is discussed in Section 4 below.

2. For an overview of disjunctivism, see Byrne and Logue (2008).

3. See, for example, the papers collected in Haddock and Macpherson (2008: Part 1), Byrne and Logue (2009), and Macpherson and Platchias (2013: Part 2).

4. Smith (2010: Section I) and Antony (2011) defend similar claims. Fish (2009: 43-46) also emphasizes that naïve realists cannot appeal to disjunctivism in order to accommodate illusions. 
does not instantiate. As a result, it seems that the naïve realist must claim that the relevant error is not contained within the perceptual experience itself but is located in some distinct judgment the experience precipitates. Naïve realism is not unique in attempting to restrict perceptual error to judgments. For instance, on the view that perceptual experiences are raw feels or brute sensations that give rise to judgments about nearby objects, perceptual experiences themselves never contain mistakes. However, on such a view, not only is perceptual error confined to judgment, but so too is perceptual success. ${ }^{5}$ Conversely, the naïve realist ascribes perceptual success to perceptual experiences themselves but confines perceptual error to judgment. I maintain that this combination is not sustainable.

First, in Sections 1 and 2, I say a bit more about illusions and explain why naïve realists can't adopt the disjunctivist strategy in order to account for such experiences. In Section 3 I consider the proposal that illusions are cases in which you are prevented from perceiving properties you would ordinarily perceive and subsequently judge that the object you perceive instantiates some property it does not instantiate. I argue that this proposal's requirement that the property an illusion concerns is absent from the phenomenology of the relevant experience is unacceptable. In Section 4 I consider and reject the suggestion that the difficulties facing this initial proposal can be overcome by appealing to the looks or appearances objects possess. Ultimately, I conclude that the naïve realist cannot provide a plausible account of illusions and that, consequently, naïve realism should be rejected.

\section{Illusions}

When you have a veridical perceptual experience you perceive a particular object and that object has precisely the properties you perceive it to have. Both illusions and hallucinations are non-veridical experiences, but illusions involve a more subtle kind of perceptual error. When you have an illusory perceptual experience you still perceive a particular object but that object does not have at least one of the properties you experience it as having. Conversely, when you have a hallucinatory perceptual experience you do not perceive a particular object at all-it merely seems that way to you.

This account of illusion won't enable us to determine whether or not a given experience is an illusion in every imaginable case; but such an account isn't required for present purposes. Instead, we can focus the discussion on a few typical examples of illusory visual experiences.

5. For discussion of this brute sensation theory see, for instance, Smith (2002: 69-90) and Siegel (2013: Section 2.1). 
First, consider the visual experience that results when you view the MüllerLyer diagram. The diagram consists of two lines of equal length, with inwardpointing arrows at the ends of one line and outward-pointing arrows at the ends of the other. When you view the diagram you perceive the lines and many of their properties. For instance, you see the colour of the lines and you see their straightness. However, the experience is illusory in that you misperceive the relative lengths of the two lines: although the lines are the same length, you experience them as being different lengths. In fact, even if you have measured the two lines and know that they are the same length you will continue to experience them as being different lengths when you view the diagram.

Second, imagine looking at a perfectly circular object through a large, strongly distorting lens that is not visible from your vantage point. ${ }^{6}$ In such a case you would perceive the circular object and many of its properties. For instance, you would see the object's colour and its distance from you. But you would not perceive the object's circularity; instead, you would experience the object as being elliptical. (This example is similar to the more frequently discussed case of the straight stick half submerged in water so as to appear bent; the difference is that in the present example the refracting medium is not visible).

Finally, imagine looking at a white wall illuminated by a red spotlight in such a way that the redness of the light is not apparent (e.g., the air is not particularly dusty and any other visible objects are reflecting light from ordinary sources). In such a case you would perceive the wall and its size, shape, and other such properties. However, you would misperceive the wall as being red when it is actually white.

\section{The Disjunctivist Strategy}

These and other similar experiences pose a more difficult problem for naïve realism than do hallucinations because they involve ordinary perceptual contact with physical objects and some of their properties. Given that when you undergo a hallucination there is no ordinary physical object that you perceive, the naive realist is essentially forced to claim that the phenomenology of hallucinatory experiences is wholly constituted by something other than acquaintance with ordinary physical objects and their properties. Conversely, because illusory experiences involve ordinary perceptual contact with physical objects and at least some of their properties, the naïve realist must grant that the phenomenology of such experiences is at least partly constituted by acquaintance with physical objects and their properties. However, once the naïve realist grants that the phe-

6. The example is borrowed from Foster (2000: 67-68). 
nomenology of illusory experiences is partly constituted by acquaintance with physical objects and their properties, she can't plausibly deny that the phenomenology of such experiences is wholly constituted by acquaintance with physical objects and their properties. ${ }^{7}$

The naïve realist must grant that the phenomenology of illusory experiences is at least partly constituted by acquaintance with ordinary physical objects and their properties for at least two reasons. First, unlike hallucinations, illusions are pervasive. Consider, for instance, our visual perception of an object's distance. Our capacity to accurately perceive how distant a given object is from us changes dramatically depending on how far away that object is: distance perception is quite accurate when objects are close at hand, but it is distorted in systematic ways as objects get farther away. ${ }^{8}$ If the naïve realist denies that illusory experiences involve acquaintance with ordinary physical objects, she must claim that when we undergo an illusory experience either we are acquainted with something other than an ordinary object (perhaps a sense-datum or a mental image) or we aren't acquainted with anything at all. But, then, the facts about distance perception would require the naïve realist to adopt the implausible view that much of the time we perceive physical objects in some way other than being acquainted with them, and only when they are close at hand do our experiences consist in acquaintance with these objects. As Smith puts it, "the picture of our daily commerce with the world through perception that therefore emerges is one of a usually indirect awareness of physical objects occasionally interrupted by direct visions of them glimpsed in favoured positions" (2002: 28). ${ }^{9}$

Second, and more importantly, every reason for thinking that the phenomenology of veridical perceptual experiences is constituted by acquaintance with ordinary objects and their properties is also a reason for thinking that the veridical aspects of the phenomenology of illusory perceptual experiences are constituted by acquaintance with ordinary objects and their properties. We can illustrate this point by considering some of the standard motivations for naïve realism. For instance, Martin claims that naïve realism is "the best articulation of how our experiences strike us as being to introspective reflection on them" (2004: 42). If that's correct, then the best articulation of how my experience of

7. Naïve realists who claim that the phenomenology of illusory experiences are not even partly constituted by acquaintance with ordinary physical objects and their properties are committed to what Byrne and Logue (2008: 69) call V v I/H disjunctivism. Naïve realists who claim that the phenomenology of illusory experiences are partly, but only partly, constituted by acquaintance with ordinary physical objects and their properties are committed to the view that perceptual experiences are divided into three categories (that there are three disjuncts): illusory experiences are not the same kind of mental state as either veridical experiences or hallucinations, but instead are some kind of hybrid composed of elements of each.

8. For a brief overview of some of the relevant evidence, see Daum and Hecht (2009).

9. Robinson (1994: 159) and Fish (2009: 44) make similar points. 
the Müller-Lyer diagram strikes me as being upon introspection is that I am acquainted with the very lines that make up the diagram, as well as their colour and shape. ${ }^{10}$ Other naïve realists claim that we have to allow that the phenomenology of veridical experiences is constituted by acquaintance with ordinary objects in order to explain the special phenomenological directness or immediacy of such experiences. ${ }^{11}$ But again, the same phenomenological considerations apply to illusory experiences: when you see the wall under the red spotlight the very wall itself seems to be directly present to you, as do certain of its properties.

Still other naïve realists appeal to the knowledge that veridical perceptual experiences provide their subjects with. For instance, Campbell claims that "experience of a perceived object is what provides you with knowledge of the reference of a demonstrative referring to it" (2002: 114). In order to explain how experiences provide such knowledge, he maintains, we must understand perceptual phenomenology to be constituted by acquaintance with ordinary objects. If so, we should draw the same conclusion with respect to illusory experiences, since an illusory experience of some object can provide you with knowledge of the reference of a demonstrative referring to it. And a similar point applies to Logue's claim that only naïve realism can explain how veridical perceptual experiences provide the perceiver with knowledge of what objects with certain properties "are like independently of experience" (2012: 231). If a veridical experience of a straight line provides me with knowledge of what straight things are like independent of my experience of them, so too does my illusory experience of the lines in the Müller-Lyer diagram.

One might think that the naïve realist can grant that the veridical aspects of the phenomenology of an illusory experience are constituted by acquaintance with an object's properties while insisting that other aspects of the experience's phenomenology are not so constituted. A defender of such a view claims that illusory experiences are a kind of hybrid, composed of both veridical and hallucinatory elements: the veridical elements of perceptual phenomenology are constituted by acquaintance with an object's properties, while the illusory elements are not (perhaps the illusory elements are constituted by acquaintance with sense-data, or by the representation of absent properties, or perhaps we can't say what constitutes them). However, a view of this sort is also unacceptable.

The principal difficulty is that such a theory is inconsistent with the fact that the distinct phenomenal features instantiated by a given perceptual experience are, to a significant extent, interdependent. For instance, as Fish (2009: 44) and

10. Smith (2010: 395-96) also notes that Martin's motivation for naïve realism applies to the non-illusory aspects of illusory experiences.

11. See, for example, Crane (2006: 139-41), Hellie (2007: 266-69), Fish (2009: 19-23), and Kennedy (2009: 578-80). 
Smith (2010: 389) note, when you see the shape of a coloured object, you see the object's shape in virtue of seeing its colour. But visual illusions often occur where the subject accurately perceives an object's shape but misperceives its colour. In such a case, then, the naïve realist can't claim that your experience's shape phenomenology is constituted by your acquaintance with the object's shape, while your experience's colour phenomenology is constituted by something else. As Smith says of a case involving the perception of a square, "if something other than the real square accounts for the appearance of the colour, something other than the real square (and its constituency) accounts for the very appearance of the square" (2010: 389 ). ${ }^{12}$

Ultimately, then, the naïve realist can't apply the disjunctivist strategy to illusions. That is, the naïve realist must claim that the phenomenology of an illusory experience, just like that of a veridical experience, is wholly constituted by acquaintance with a given object and certain of its properties. But then it would seem that the property an illusion concerns can't be part of the relevant experience's phenomenology (since you can't be perceptually acquainted with a property the object doesn't instantiate). Accordingly, the difficult task the naïve realist faces is to provide a plausible account of what's gone wrong in cases of illusion while denying that the relevant error is located within the phenomenology of the experience itself.

\section{Judgments}

A first option available to the naive realist would be to claim that the characteristic feature of illusions is that the subject is prevented from perceiving properties that he would ordinarily perceive. The element that prevents the subject from being acquainted with the relevant property will vary from case to case. Often it will be some environmental feature. For example, your visual experiences typically acquaint you with an object's colour, but an undetected red spotlight might prevent you from seeing a white object's whiteness. In other cases it might be some psychological feature of the perceiver. For instance, perhaps the arrows in the Müller-Lyer diagram produce a response in your visual system that prevents you from seeing that the lines are the same length. ${ }^{13}$

But, of course, there is no error involved in simply failing to perceive some property instantiated by a perceived object. We don't see the interiors of most of the objects we perceive, but we don't thereby misperceive them. Consequently, a naïve realist defending the present approach to illusion must appeal to a mis-

12. Smith (2010: 389-390) also extends this argument to cover a negative disjunctivist variety of this view.

13. Fish (2009: 173-74) offers this suggestion. 
taken judgment. That is, the present proposal is that an illusory experience is one where you are prevented from perceiving some property that you would normally perceive and subsequently judge that the object instantiates a property that it does not instantiate. The error, then, is not contained in the experience itself but in a judgment the experience precipitates.

In order to evaluate this approach it will help to introduce a more detailed example. So, consider Fish's (2009: 161-65) account of the illusion that occurs when you view a circular object through a distorting lens. Fish claims that you can see certain of the object's properties in this situation but that the lens prevents you from perceiving properties you would normally perceive. Specifically, while you see, amongst other things, the object's colour and its distance from you, the way the lens refracts light prevents you from being acquainted with the object's shape. The negative role that the lens plays in producing the illusion is that it prevents you from being acquainted with the object's circularity and thereby stops your experience from having a certain specific phenomenal feature. Looking at the object through the lens does not result in an experience with a phenomenological ellipticalness - there is no elliptical aspect of the phenomenology of your perceptual experience because you are not acquainted with an elliptical object. The illusion of ellipticalness, then, only enters the picture when you judge that the object is elliptical. On Fish's view, because you aren't aware of the lens and how it refracts the light, your visual experience leads you to judge (in a passive or purely automatic fashion) that the object is elliptical. ${ }^{14}$

A natural objection to Fish's account of this illusion is that it contradicts what we know about the phenomenology of the experience through introspection. Specifically, one might think that it's clear from introspection that Fish's claim that your visual experience of the circular object lacks shape phenomenology is false. For instance, imagine a situation where you view an elliptical object of the right sort through a flat pane of glass: presumably such an experience would have precisely the same shape phenomenology as your illusory experience of the circular object viewed through the lens. But Fish must deny that assumption. According to him, while your veridical experience has a phenomenal feature consisting of you being acquainted with the object's ellipticalness, the illusory experience lacks this feature. And yet, so the objection goes, we know through introspection that the illusory experience possesses the same shape phenomenology as a veridical experience of an elliptical object.

14. Fish (2009: 167-69) talks in terms of the "passive deployment" of a "conceptualrecognitional capacity" rather than in terms of judgment, but the difference shouldn't matter for present purposes. In any case, given that Fish (2009: 73) characterizes a "recognitional capacity" as the ability to have acquaintance with a certain property figure in the phenomenology of one's perceptual experiences, it doesn't seem that this ability could be exercised in cases where the perceived object doesn't instantiate the property in question. 
Fish's response to this objection is to insist that you are mistaken in thinking that your illusory visual experience possesses the phenomenal feature at issue. However, he grants that it seems to you to possess this feature, and he has a straightforward explanation of why it seems this way to you: because you are not aware of the lens, your experience leads to a spontaneous judgment that the object is elliptical (Fish 2009: 169-72). ${ }^{15}$ This judgment will lead you to believe that you are seeing an elliptical object and therefore that your visual experience has the phenomenology characteristic of veridical visual experiences of elliptical objects. ${ }^{16}$ So, according to Fish, your mistake about what you are seeing can't help but produce a mistake about the phenomenology of your visual experience; and consequently, the appeal to introspection on which the present objection rests is without force.

However, we needn't rely on appeals to introspection of this sort in order to establish that the illusory experience of the circular object possesses the relevant shape phenomenology. Instead, we can appeal to the fact, mentioned above, that the distinct phenomenal features instantiated by a given perceptual experience are interdependent. For instance, it's because you can discriminate the object's colour from that of the background that you can see where the object ends and the background begins; and by determining the object's boundaries in this manner you perceive its shape. Consequently, the particular shape phenomenology the experience instantiates results in part from the perception of the object's colour. Moreover, colour and shape are not unique in this regard: the phenomenal features associated with shape, size and distance depend on one another in similar ways.

Given this interdependence between the distinct aspects of perceptual phenomenology, the naïve realist cannot plausibly deny that your illusory experience in the case at hand possesses the relevant shape phenomenology. In fact, when he discusses cases where a subject misperceives an object's colour despite accurately perceiving its shape, Fish (2009: 151) is careful to deny that the relevant experiences lack colour phenomenology. His reasoning is that if an experience in such a case lacked colour phenomenology, it wouldn't be possible

15. Pautz (2013: 31) objects that if Fish is correct, we can't appeal to your visual experience to explain why you judge that the object is elliptical, nor can we say that your judgment is justified. See Fish (2013: 60-61) for a response.

16. Another difficulty worth mentioning is that lenses of slightly different strengths would produce a number of distinct illusory experiences that the subject would be able to discriminate. But since on Fish's account all of the resulting experiences would have the same shape phenomenology (namely none), the subject's capacity to discriminate between these experiences would have to be explained in terms of the judgments the subject makes about the shape of the object. The difficulty, then, is that these judgments employ concepts, and it's not clear that you have concepts of all the different illusory ellipses you could distinguish (that is, your shape concepts are not sufficiently fine-grained). 
for the subject to accurately perceive the object's shape. But the converse of this reasoning applies to the present case: if you accurately perceive the object's colour it won't be possible for your experience to lack shape phenomenology. As Fish (2009: 164) acknowledges, when you perceive the circular object through the lens you are acquainted with its colour and its being "a bounded figure"; but if your experience possesses the phenomenal features associated with perceiving a coloured object with distinct boundaries, your experience will thereby possess shape phenomenology.

Consequently, the present naïve realist account of illusion fails. The naïve realist cannot plausibly claim that your experience in this case lacks shape phenomenology but leads you to judge that the object is elliptical, because she cannot plausibly claim that this experience lacks shape phenomenology. So, if we assume that the illusion consists in the fact that you perceive the object as being elliptical when it is actually circular, this ellipticalness that you attribute to the object must be part of your experience's perceptual phenomenology. It won't do, then, to think of the judgment that the object is elliptical as a distinct mental state; rather, this judgment would have to partly constitute the experience itself. But, of course, someone who claims that representing that an object is elliptical is sufficient for ellipticalness to figure in perceptual phenomenology thereby denies that the phenomenology of an illusory experience is wholly constituted by acquaintance with a physical object and certain of its properties. In short, if the illusion consists in perceiving the object as being elliptical when it is actually circular, then ellipticalness must be present in the phenomenology of your experience; but if naïve realism is true then ellipticalness can't be present in the phenomenology of your experience precisely because the object you see isn't elliptical.

\section{Looks}

I have been assuming to this point that the property any given illusion concerns is a property that the perceived object does not instantiate. This assumption is extremely natural (in fact, it's difficult to explain what illusions are supposed to be without making this assumption). For instance, in the case of the circular object viewed through the distorting lens it's natural to assume that the illusion consists in the fact that you experience the object as being elliptical when it is not elliptical. But if that assumption is correct then the naïve realist is in trouble, since she will have to locate the misattribution of the relevant property in some distinct judgment the experience precipitates, and such a view is problematic for the reasons just outlined.

However, the naïve realist might be able to account for illusions while re- 
jecting this assumption. That is, the naïve realist can claim that what makes an experience illusory is not that you experience the perceived object as having some property it lacks, but that you perceive a special sort of property that it instantiates - a property that is typical or characteristic of a kind of which the object you perceive is not an instance. This special sort of property will be a look or appearance, where these are understood to be mind-independent properties of objects with which subjects can be perceptually acquainted. ${ }^{17}$ For instance, the naïve realist might say that the circular object viewed through the distorting lens has an appearance that is characteristically instantiated by elliptical objects. What makes your experience an illusion is not that you experience the object to be elliptical; rather, it's that you are acquainted with a look characteristic of elliptical objects that the circular object you perceive happens to instantiate in the present circumstances.

There are two reasons for thinking that this general approach to illusion is ultimately unsuccessful. First, the naïve realist needs to provide some account of the nature of these looks or appearances; but there is no account of the nature of these properties consistent with naïve realism that will help explain the illusions at issue. Second, even if the naïve realist could produce a plausible account of what looks are, being acquainted with such properties would not be sufficient for suffering an illusion-it would still be necessary to appeal to a judgment the subject makes misattributing some property to the perceived object. And consequently, invoking looks would not enable the naïve realist to avoid the difficulties discussed in the previous section. I will discuss each of these problems in turn.

\subsection{The Nature of Looks}

According to one standard account of looks or appearances, they are defined in terms of the experiences objects cause perceivers to undergo. For instance, what Shoemaker calls "occurrent appearance properties" consist in an object's "actually causing experiences of a certain sort in a perceiver"; and what he calls "dispositional appearance properties" consist in an object's "being disposed to produce experiences of a certain sort in perceivers of one or more sorts" (2006: 465). However, a naïve realist can't appeal to such properties because he thinks

17. A number of philosophers have provided accounts of illusion that appeal to looks understood along these lines. See, for example, Travis (2004), Antony (2011), Kalderon (2011), and Genone (2014). Brewer's (2011: Chapter 5) account of illusion also appeals to "looks," but he does not take these to be mind-independent properties of objects with which subjects can be perceptually acquainted (see Footnote 18 below). Martin (2010) characterizes looks as mind-independent properties of objects, but because he identifies such properties with basic visible properties such as shape, size, and colour, appealing to looks as Martin understands them would not help the naïve realist provide an account of illusion. 
having an experience just is being acquainted with an object and some of its properties (the properties you can be perceptually acquainted with will have to be experience-independent properties).

A related possibility would be to appeal to some of the non-experiential effects that objects have on perceivers. For instance, Brewer claims that experiences are illusory just in case the perceived objects have "visually relevant similarities" with "paradigm exemplars of kinds of which they are not in fact instances" (2011: 102). One such similarity concerns "the way in which stimuli are handled by the visual system, given its evolutionary history and our shared training during development" (2011: 103). ${ }^{18}$ Accordingly, the naïve realist might propose that having a look is a matter of having the property of causing certain neurological events in the perceiver's brain. For instance, one might claim that when you view the Müller-Lyer diagram you are acquainted with the line's property of causing a specific pattern of neurological activity in your brain that is characteristically caused by lines of equal length. However, the difficulty with such a proposal is that it requires that perceivers be visually acquainted with what a particular stimulus is doing to their brains, and we simply don't see such properties. ${ }^{19}$

A more promising strategy, then, might be to appeal to relational properties with which perceivers are plausibly visually acquainted. Specifically, one might

18. A crucial difference between the various Brewer-inspired proposals described in this section and Brewer's actual view is that Brewer defends a non-standard variety of naïve realism according to which subjects are perceptually acquainted only with objects and not with their properties. The arguments in this section target the version of naive realism according to which looks are properties of objects with which subjects are perceptually acquainted. Nonetheless, I believe that Brewer's view faces closely related difficulties. For Brewer, for an object to look F just is for it to have, relative to a certain vantage point and under certain viewing conditions, "visually relevant similarities" with paradigm F objects (2011: 102). But a given object will have such similarities with very many different objects of different kinds. For instance, the circular object viewed through the lens has visually relevant similarities both with paradigm circular objects and with paradigm elliptical objects. So what, on Brewer's account, makes it the case that the experience of this object constitutes an illusion? He might claim that the circular object possesses "sufficiently many" or "all the appropriate" visually relevant similarities with paradigm elliptical objects, but not with paradigm circular objects (2011: 103, Footnote 8). But then it's not clear what it is for an object to have "sufficiently many" or "all the appropriate" similarities with a paradigm of a certain kind. Alternatively, he might appeal to the fact that the subject "recognizes" or "registers" the similarities with paradigm elliptical objects (2011: 121-22). But such an account is unacceptable for two reasons: first, the subject of the illusion will not be in a position to recognize the similarities at issue because she will be completely unaware of them; second, simply recognizing that a circular object has certain similarities with paradigm elliptical objects is not thereby to suffer an illusion (see Section 4.2 below).

19. Smith (2010: 393) makes a similar point. It's also worth noting that because we don't see such properties, illusions that are due entirely to changes occurring within the perceiver constitute a particularly difficult challenge to an account of illusion that appeals to looks: see Byrne (2009: 446-47) and Smith (2010: 392, Footnote 12). 
appeal to the extrinsic properties an object instantiates that change with changes to viewing conditions: the direction and quality of the light hitting the object, the orientation of the object relative to the perceiver's vantage point, the visual angle the object subtends, and so on. ${ }^{20}$ Modifying some terminology from Schellenberg (2008), I'll call such properties of objects situational properties. So, for instance, one might claim that when you view the circular object through the lens you are acquainted with a certain specific situational property it instantiates that is characteristically instantiated by elliptical objects viewed under standard conditions. ${ }^{21}$

However, if the naïve realist equates looks with situational properties, she won't be able to appeal to looks in order to account for illusions. A first obstacle is that, thanks to perceptual constancy mechanisms, even significant variations in situational properties do not usually produce illusory visual experiences. Consider, for instance a typical example of shape constancy: when you view a tilted penny you might see that the visual angles it subtends in various dimensions are identical to those subtended by a paradigm elliptical object viewed head on; nonetheless you still see that the penny is circular.

A second, more significant difficulty is that, at least in many of the sorts of illusions at issue, there are no appropriate situational properties that the naïve realist can plausibly invoke. Regarding the Müller-Lyer diagram, Brewer (2006: 16869; 2011: 102) points to the fact that under normal viewing conditions the lines subtend the same visual angle, just as a paradigm example of two unequal lines at slightly different distances from the perceiver do. But, of course, a paradigm example of two equal lines at the same distance from the perceiver also subtend the same visual angle, so this situational property is not suggestive of inequality in length. (Brewer suggests that the arrows in the Müller-Lyer diagram operate as misleading depth cues, but the arrows can be replaced with circles and the illusion is unaffected). And regarding the circular object viewed through the lens, the presence of the lens does not seem to alter any pertinent shape-related situational features. When discussing the similar case of the straight stick half submerged in water, Brewer claims that the visually relevant similarity between the straight stick and a paradigm bent stick is that in the region of space "above the refracting surface of the liquid ... light from corresponding parts of the two sticks travels, or would travel, along the same paths" (2011: 106). But, first, the path that light travels between some particular point in space and your eye is not something you can visually perceive. And, second, unlike the case of the stick in water, once the light reflected by the circular object has passed through the

20. The role such properties play in perception is discussed, for instance, by Noë (2004: Chapter 3), Schellenberg (2008), and Hill (2009: Chapter 5).

21. Fish (2009: 160-61) claims that at least certain sorts of illusions can be explained in terms of the perceiver's acquaintance with situational properties. See, also, Brewer (2011: 106). 
refracting medium of the lens, it does not travel along the same path that light reflected by an elliptical object would travel. ${ }^{22}$

Finally, the naïve realist might endorse Genone's (2014: Sections 4-5) view that looks are constituted by how an object's intrinsic properties, like shape and colour, relate to environmental features, such as lighting conditions. Genone's account of looks differs from the previous account in that he denies that objects with a variety of different intrinsic properties under different viewing conditions can share a particular look. For instance, a white wall illuminated by red light and a red wall illuminated by white light share a particular situational property: they both reflect light of a certain quality. But according to Genone, being white and reflecting red light is a distinct look from being red and reflecting red light. As a result, a naïve realist appealing to Genone's account of looks cannot claim that illusions occur when you are acquainted with a look that is characteristic of objects with a certain property that the object you perceive lacks; instead, he would have to claim that illusions occur when you perceive a look that the object possesses that you cannot discriminate from some distinct look.

However, looks understood along these lines can't help the naïve realist account for illusions. For instance, the initial motivation for appealing to looks in the case of the circular object viewed through the distorting lens is that, since you don't see the object's circularity and can't see its ellipticalness, the naïve realist wants to find some distinct property the perceived object instantiates - a particular look - with which you are acquainted. Conversely, on Genone's view you can see the object's circularity: the relevant look in this example is the object's being circular and reflecting light that is refracted by a lens. But, if so, then the naïve realist cannot appeal to the object's look in order to explain why you are not able to discriminate the object from an elliptical object. ${ }^{23}$

\subsection{The Insufficiency of Looks}

Suppose, for the sake of argument, that the naïve realist can pinpoint some spe-

22. The situational property Brewer (2011: 106) appeals to in the case of a white object illuminated by red light is the quality of the light the object reflects (i.e., the object reflects light of the same quality that a paradigm red object would reflect). Smith (2010:393) objects that we do not see the quality of the light that a surface has reflected.

23. Genone's (2014: Sections 5-6) own account of illusions appeals to mistaken judgments. Specifically, he claims that illusions occur when your acquaintance with a particular look the perceived object instantiates leads you to make a false judgment, due to your lack of familiarity with the relevant environmental conditions. However, Genone can't claim that you are unfamiliar with the relevant environmental conditions since, on his view, they are part of the looks that you see. So, for instance, in the case at hand there is no reason whatever for you to judge that the circular object is elliptical because you are visually acquainted with the object's circularity and with its property of reflecting light that is refracted by a lens. 
cific mind-independent properties of objects with which looks can plausibly be identified. Suppose also that in every relevant case of illusion the perceived object instantiates a look that is characteristic of objects with some property that the perceived object lacks. Even so, the present account of illusion fails. According to the proposal at issue, what makes an experience illusory is not that you experience the perceived object as having some property it lacks, but that you perceive a look characteristic of a kind of which the object you perceive is not an instance-perceiving this look is sufficient for suffering the illusion. But whatever looks are, perceiving such properties is not sufficient for suffering an illusion.

Again, the present proposal is that in cases of illusion, the perceived object, $\mathrm{O}$, has a look, $\mathrm{L}$, that is also instantiated under certain viewing conditions by paradigm examples of objects with a particular property, F, and $\mathrm{O}$ is not F. In all such cases, $\mathrm{L}$ and $\mathrm{F}$ are distinct properties that tend to go together: under certain viewing conditions, paradigm examples of objects that instantiate $\mathrm{F}$ also typically instantiate $\mathrm{L}$. The problem, then, is that even if $\mathrm{L}$ and $\mathrm{F}$ tend to be found together in certain relevant cases, perceiving $\mathrm{L}$ in the absence of $\mathrm{F}$ does not thereby constitute a perceptual error of any kind. That is, perceiving an object that is not $\mathrm{F}$ but that possesses a look that F objects characteristically possess just isn't to suffer an illusion.

Typical examples of perceptual constancy illustrate the difficultly. On any pertinent account of looks, when you view a tilted penny it will instantiate a look that paradigm elliptical objects instantiate; but, even assuming that you perceive this look you do not misperceive the penny. You perceive the penny to be circular rather than elliptical (which it is) and you perceive it to have a certain look, one that is shared by elliptical objects viewed head on (which it has). Or, imagine that you see a uniformly white cube lit in such a way that one of its faces is darker than the rest due to an attached shadow. In such a situation the relevant surface will possess a look that paradigm grey objects instantiate under direct lighting; but when you view the cube, even assuming that you perceive that this surface has the look at issue, you accurately perceive that it is white. These cases involve perfectly veridical experiences, yet the present account classifies them as illusions.

One way to respond to this problem might be to appeal to recognizing that a particular look is characteristic of a certain sort of object. For instance, Brewer (2011: 121-27) claims that we sometimes 'register' or 'notice' that a given object has a look shared by paradigm examples of objects of a certain kind. Perhaps, then, the naïve realist can claim that your experience of the circular object through the lens is illusory because you notice that it has a look that paradigmatic elliptical objects possess, whereas your experience of the tilted penny is not illusory because you fail to notice that the penny has this look.

However, appealing to acts of recognition is no help. The looks objects pos- 
sess may typically go unnoticed, but you can turn your attention to them without suffering an illusion. When I notice that the tilted penny has a look that paradigmatic elliptical objects possess I don't thereby misperceive the penny. I still perceive the penny to be circular; all I've done is shifted my attention to one of the penny's properties that I usually ignore. By way of analogy, James might be speaking with an accent that Australians characteristically speak with, despite not being Australian himself. I might hear James speaking and notice that he is speaking with an accent that Australians characteristically speak with without forming any false beliefs. Given that I can hear James speaking and notice that he speaks with an accent typical of Australians, it might be perfectly natural for me to infer that he is Australian; but so long as all I do is notice this feature of James's speech, I have not made an error of any kind.

The foregoing might suggest that, in order to provide a satisfactory account of illusions, a naïve realist who invokes looks or appearances will have to appeal to judgments that perceivers make in response to being acquainted with such properties. For instance, Genone (2014) claims that illusions occur when a subject judges that the perceived object instantiates a property it does not in fact instantiate as a result of being acquainted with a particular look that the object has. However, such a view is committed to the assumption we were trying to avoid: that the property any given illusion concerns is a property that the perceived object does not instantiate.

If the naïve realist endorses this assumption, he faces the difficulties discussed above (Section 3); and appealing to looks will not help him avoid them. A naïve realist of this sort will claim that the case of the circular object viewed through the lens is an illusion in virtue of the fact that you judge that the object is elliptical. Appealing to a special look the circular object has under these circumstances might help explain why you judge that the object is elliptical, but it doesn't help answer the difficult questions regarding the experience's shape phenomenology. According to the present account, when you view an elliptical object through a flat piece of glass you are acquainted with the object's ellipticalness as well as the relevant look; so acquaintance with these two distinct properties constitutes two distinct aspects of your experience's phenomenology. But when you view the circular object through the lens, the naïve realist must claim that your experience possesses look-related phenomenology yet lacks any shape-related phenomenology. After all, you aren't acquainted with the object's ellipticalness since it isn't elliptical, and, thanks to the interference of the lens, neither are you acquainted with its circularity (if you were acquainted with both the object's look and its circularity, the result would be an ordinary case of shape constancy-you would be no more likely to judge that the object is elliptical than you are to judge that the tilted penny is elliptical). And, again, the claim that this experience lacks shape 
phenomenology is unacceptable given the interdependence amongst different aspects of perceptual phenomenology. The look phenomenology cannot take the place of or stand in for the shape phenomenology-because the experience possesses the phenomenal features associated with perceiving a coloured object with distinct boundaries, it will thereby possess shape phenomenology regardless of whatever additional look-related phenomenological features it possesses.

\section{Conclusion}

Ultimately, then, appealing to looks or appearances won't enable the naïve realist to deny the natural assumption that the property any given illusion concerns is a property that the perceived object does not instantiate. For instance, the only plausible characterization of the illusion involved when you view the circular object through the lens is that you experience the object as being elliptical. But once this assumption is granted, the naïve realist is forced to claim that a given property is a constituent of perceptual phenomenology in veridical cases but is absent from perceptual phenomenology in illusory cases. The resulting view is that when you have a veridical experience of an elliptical object, acquaintance with that object's shape constitutes a phenomenal feature of your experience; and when you suffer a corresponding illusion, your experience lacks any shape phenomenology, and you merely judge that the object is elliptical. However, given that when you misperceive an object's shape you are acquainted with other sensible properties such as its colour, and given that the distinct aspects of perceptual phenomenology are interdependent, shape phenomenology can't simply be absent form such an experience.

The problem is not simply that the naïve realist must explain perceptual error in terms of judgment. A defender of a brute sensation theory of perceptual experience doesn't face the same difficulty despite explaining illusions in terms of mistaken judgments. The crucial difference is that a brute sensation theorist will grant that a veridical experience of an ellipse and a corresponding illusory experience have precisely the same perceptual phenomenology-a point he can grant because he claims that the attribution of shape to an object always involves the perceiver making a judgment. Conversely, the naïve realist claims that the attribution of shape to an object is sometimes a component of perceptual phenomenology and sometimes not. It is the naïve realist's attempt, then, to ascribe perceptual success with respect to a given property to perceptual experiences themselves while confining perceptual error with respect to that same property to judgment that leads to intractable difficulties. 


\section{Acknowledgments}

Thanks to Bill Brewer, William Fish, James Genone, and three anonymous referees for Ergo for comments that lead to significant improvements to this paper.

\section{References}

Antony, Louise (2011). The Openness of Illusions. In Ernest Sosa and Enrique Villanueva (Eds.), Philosophical Issues 21: The Epistemology of Perception (25-44). Wiley-Blackwell. Brewer, Bill (2006). Perception and Content. European Journal of Philosophy, 14(2), 165-81. Brewer, Bill (2011). Perception and Its Objects. Oxford University Press.

Byrne, Alex (2009). Experience and Content. Philosophical Quarterly, 59(236), 429-51.

Byrne, Alex and Heather Logue (2008). Either/Or. In Adrian Haddock and Fiona Macpherson (Eds.), Disjunctivism: Perception, Action, Knowledge (57-94). Oxford University Press.

Byrne, Alex and Heather Logue (2009). Disjunctivism: Contemporary Readings. MIT Press. Campbell, John (2002). Reference and Consciousness. Oxford University Press.

Campbell, John (2009). Consciousness and Reference. In Brian McLaughlin, Ansgar Beckermann, and Sven Walter (Eds.), The Oxford Handbook of Philosophy of Mind (648662). Oxford University Press.

Crane, Tim (2006). Is There a Perceptual Relation? In Tamar Szabó Gendler and John Hawthorne (Eds.), Perceptual Experience (126-46). Clarendon Press.

Daum, S. Oliver and Heiko Hecht (2009). Distance Estimation in Vista Space. Attention, Perception, \& Psychophysics, 71(5), 1127-137.

Fish, William (2009). Perception, Hallucination, and Illusion. Oxford University Press.

Fish, William (2013). Perception, Hallucination, and Illusion: Reply to my Critics. Philosophical Studies, 163(1), 57-66.

Foster, John (2000). The Nature of Perception. Oxford University Press.

French, Craig (2014). Naive Realist Perspectives on Seeing Blurrily. Ratio, 27(4), 393-413.

Genone, James (2014). Appearance and Illusion. Mind, 123(490), 339-76.

Haddock, Adrian and Fiona Macpherson (2008). Disjunctivism: Perception, Action, Knowledge. Oxford University Press.

Hellie, Benj (2007). Factive Phenomenal Characters. In John Hawthorne (Ed.), Philosophical Perspectives 21: Philosophy of Mind (259-306). Blackwell.

Hill, Christopher (2009). Consciousness. Cambridge University Press.

Kalderon, Mark Eli (2011). Color Illusion. Noûs, 45(4), 751-75.

Kennedy, Matthew (2009). Heirs of Nothing: The Implications of Transparency. Philosophy and Phenomenological Research, 79(3), 574-604.

Logue, Heather (2012). Why Naïve Realism? Proceedings of the Aristotelian Society, 112(2), 211-37.

Macpherson, Fiona and Dimitris Platchias (2013). Hallucination. MIT Press.

Martin, M. G. F. (2004). The Limits of Self-Awareness. Philosophical Studies, 120(1), 37-89.

Martin, M. G. F. (2010). What's In a Look? In Bence Nanay (Ed.), Perceiving the World (160-225). Oxford University Press.

Noë, Alva (2004). Action in Perception. MIT Press. 
Nudds, Matthew (2009). Recent Work in Perception: Naïve Realism and its Opponents. Analysis 69(2), 334-46.

Pautz, Adam (2011). Can Disjunctivists Explain Our Access to the Sensible World. In Berit Brogaard, Ernest Sosa, and Enrique Villanueva (Eds.), Philosophical Issues 21: The Epistemology of Perception (384-433). Wiley-Blackwell.

Pautz, Adam (2013). Do the Benefits of Naïve Realism Outweigh the Costs? Comments on Fish, Perception, Hallucination and Illusion. Philosophical Studies, 163(1), 25-36.

Robinson, Howard (1994). Perception. Routledge.

Schellenberg, Susanna (2008). The Situation-Dependency of Perception. The Journal of Philosophy, 105(2), 55-84.

Shoemaker, Sydney (2006). On the Way Things Appear. In Tamar Szabó Gendler and John Hawthorne (Eds.), Perceptual Experience (461-80). Clarendon Press.

Siegel, Susanna (2013). The Contents of Perception. In Edward Zalta (Ed.) The Stanford Encyclopedia of Philosophy. Retrieved from http://plato.stanford.edu/archives/ fall2013/entries/perception-contents/

Smith, A. D. (2002). The Problem of Perception. Harvard University Press.

Smith, A. D. (2010). Disjunctivism and Illusion. Philosophy and Phenomenological Research, $80(2), 384-410$.

Travis, Charles (2004). The Silence of the Senses. Mind, 113(449), 57-94. 
